\title{
Contribuição ao estudo da ação central da mianesina
}

\author{
por
}

\section{Helion Povoa Filho}

1) Ação sôbre as convulsões espinhais

2) Ação sôbre o tônus muscular

Durante investigações sôbre as propriedades farmacológicas dos éteres $\alpha$-substituidos do glicerol, BERGER e BradLEy, na British Drug Houses, observaram que, administrando-se alguns dêstes éteres a animais de experiências (ratos, cobaias, camondongos), surgia uma paralisia com profundo relaxamento muscular (7) .

A mianesina, o $\alpha$ - $\beta$-dihidroxi- $\gamma$-(2-metilfenoxi)-propano revelou-se a mais potente destas substâncias, assim como também a que exibia mais ampla margem terapêutica .

Passemos em resumo as suas principais propriedades físicas, químicas e farmacológicas.

\section{1) PROPRIEDADES FÍSICAS E QUÍMICAS}

A mianesina é um sólido branco, cristalino, de ponto de fusão 70-710 $\mathrm{C}$, de coeficiente de solubilidade $1.09 \mathrm{~g} .100 \mathrm{ml}$ de água, a $22^{\circ} \mathrm{C}$. de uréia.

É muito solúvel no álcool, propilenoglicol assim como nas soluções

Suas soluções são muito estáveis e não se alteram por ação do ar, da luz, do frio ou do calor. $(1,2)$.

\section{2) PROPRIEDADES FARMACOLÓGICAS}

\section{a) Sistema cardiovascular e respiração}

Em doses de $10 \mathrm{mg} / \mathrm{Kg}$, usando gatos ou coelhos anestesiados, não há alteração da respiração e pressão sanguínea. Doses maiores provocam a queda transitória da pressão sanguínea, bradicardia e decréscimo do ritmo dos movimentos respiratórios, que, contudo, se tornam mais amplas (5) . 


\section{b) Transmissão neuro-muscular}

A injeção intravenosa de mianesina, em dose de $50 \mathrm{mg} \mathrm{Kg}$, em gatos descerebrados, não altera a excitabilidade indireta do gastrocnêmio. Em ratos, após $500 \mathrm{mg} \mathrm{Kg}$, a resposta ao estímulo indireto não se faz presente, processando-se contudo à excitação direta (8) .

Também, em rãs européias (Rana temporaria), com doses produzindo paralisia reversível, a ação curarizante fica evidenciada (7).

Contudo, Finkelman e Ariefr negam a ação curarizante da mianesina, em experiências realizadas com rãs e gatos (9) .

\section{c) Anestesia local}

A ação anestésica local desta substância assemelha-se à da procaina, possuindo cêrca de $2 / 3$ de sua atividade(8) .

\section{d) Sistema nervoso central}

A mianesina possui nítida ação central . Assim provoca a diminuição e mesmo abolição dos reflexos espinhais de flexão e extensão contralateral, com doses inferiores à paralisante. O reflexo patelar, todavia, sofre pouca alteração, o que vem a sugerir ação interneuronal da mianesina, mercê da ação seletiva da mesma sôbre os reflexos de mais de 2 neurônios (5) .

A inibição e a facilitacão do reflexo patelar, resultantes do estímulo cortical, são abolidas com doses relativamente pequenas(14).

Finkelman e Dobin, estimulando o córtex de gatos, por aplicação de estriquinina, registraram os potenciais do córtex e da pirâmide, podendo observar que os primeiros prosseguem, ao passo que os últimos são abolidos após injeção de $30 \mathrm{mg} / \mathrm{Kg}$ de mianesina, por via intravenosa. Daí, concluiram que esta substância não age sôbre as células corticais, mas impede a transmissão através das vias eferentes subcorticais (15).

Cumpre, também assinalar a poderosa ação anticonvulsivante da mianesina em relação às convulsões eletricamente induzidas no rato e no coelho (16) e às convulsões pela estriquinina $(5,6,7)$.

\section{f) Importância clínica}

Mallinson, incumbido pela B.D.H., de investigar as aplicações clínicas da mianesina, ficou impressionado com as vantagens que a mesma apresentava, qualificando-a como o "maior avanço na anestesia desde a introdução do tionembutal", graças ao relaxamento muscular que produz (13). Além da ação coadjuvante na anestesia, a mianesina é usada no parkinsonismo, nos movimentos coreicos e atetósicos e nos estados espásticos e convulsivos. 


\section{g) Metabolismo}

A mianesina é prontamente metabolizada no organismo. Em urinas de pacientes parkinsonianos, tratados com esta substância, foram isolados 2 ácidos orgânicos: um é o ácido $\beta$-o-toloxilático e o outro, excretado em muito menor quantidade, parece ser um composto representando um degrau próximo na degradação da mianesina.

Convém frisar que ambos não possuem a atividade própria desta substância (2) .

Neste trabalho, estudaremos primeiramente a ação da mianesina sôbre o organismo do Leptodactylus ocellatus, a rã do Rio de Janeiro. Em seguida, focalizaremos a ação anticonvulsivante desta substância em relação às convulsões da crioepilepsia e da estriquinina, produzidas no mesmo animal.

Finalmente, trataremos da ação da mianesina sôbre a contratura reflexa da pata do coelho espinhal provocada pelo arrancamento da pele da mesma.

\section{AÇÃO DA MIANESINA SÔBRE O ORGANISMO INTACTO}

Utilizamos, em nossas experiências, uma solução injetável a $10 \%$, da B.D.H., que era convenientemente diluída em Ringer de rã e injetada no saco linfático ventral do animal de experiência. Num total de 70 rãs injetadas com doses variando de 25 a $250 \mathrm{mg} / \mathrm{Kg}$, pudemos observar o seguinte:

As doses abaixo de $40 \mathrm{mg} / \mathrm{Kg}$ não provocam aparentemente alterações no estado geral da rã, que prossegue com sua vivacidade normal e saltando coordenadamente. Nota-se, todavia, que, às vêzes, o reflexo de correção, ao ser o animal colocado de costas se faz com ligeiro atrazo.

As doses compreendidas entre 40 e $150 \mathrm{mg} / \mathrm{Kg}$ provocam ao fim de alguns minutos sinais como: diminuição do reflexo de correção e, por vêzes, abolição do mesmo, certa lentidão nos saltos com nítida dificuldade em sua realização, persistindo contudo coordenados, e hipotonia no trem posterior do animal, sinais êstes tanto mais evidentes, quanto maior tiver sido a dose administrada.

A rã porém continua apresentando movimentos voluntários vivos e, por excitação mecânica das extremidades dos dedos, obtemos respostas reflexas dos membros.

Em algumas experiências, foi possível observar-se que, após um certo tempo (cêrca de uma hora e meia para doses compreendidas entre 100 e $150 \mathrm{mg} / \mathrm{Kg}$ ), houve uma certa melhoria no estado geral da rã, traduzindo-se por maior vivacidade na execução dos saltos e menor dificuldade em realizar-se a correção. 
As doses compreendidas entre 150 e $250 \mathrm{mg} \mathrm{Kg}$ provocam fenômenos semelhantes, embora mais acentuados. Assim é o reflexo de correção abolido na maioria das vêzes, permanecendo também o animal em estado de imobilidade e extrema atonia. Excitações das extremidades dos dedos provocam respostas reflexas dos membros, em geral diminuidas na sua intensidade.

Não sofrem alteração aparente os reflexos corneanos assim como os movimentos respiratórios.

A rã permanece por algumas horas (2 a 3 aproximadamente) neste estado, observando-se o desaparecimento dos sinais já indicados muito lenta e progressivamente.

\section{AÇÃO DA MIANESIA SÔBRE AS CONVULSÕES DA CRIOEPILEPSIA}

Antes de estudá-la, convém explicar succintamente a natureza do fenômeno da crioepilepsia:

Em 1933, Miguel Ozorio de Almeida descobriu, ao fazer experiências com uma preparação de rã espinhal, um fenômeno, que consistia no seguinte: o resfriamento da medula espinhal, a 4 ou $5^{\circ} \mathrm{C}$, em Ringer, estando o resto da preparação à temperatura ambiente, ocasionava ataque epileptiforme típico no trem posterior do animal. Denominou-se êste fenômeno de crioepilepsia e constituiu-se êle no ponto de partida de uma série de pesquizas até hoje continuando a se processar.

Antes, porém, cumpre frisar a importância da crioepilepsia: constituiu-se ela na primeira tentativa coroada de êxito na obtenção de uma epilepsia de origem espinhal.

Com efeito, desde a clássica descoberta de Fritsch e Hitzig que produziram ataques epileptiformes, por excitação elétrica dos centros motores cerebrais, tentou-se a obtenção de convulsões por meio da excitação de outros centros nervosos, inclusive a medula espinhal.

No que diz respeito, todavia, a esta última, as tentativas da maioria dos pesquisadores, com o fito de obter fenômenos convulsivos viram-se totalmente frustadas, ocasionando a declaração em 1926 de KINNIER WILson: "segundo me consta, ainda não foi encontrada uma epilepsia estritamente espinhal, embora não exista impossibilidade teórica em sua produção".

\section{Descrição do ataque}

$O$ ataque nunca falta no Rio de Janeiro, abaixo dum limite superior de temperatura que é de $8,5^{\circ}$ em média.

Colocando a medula espinhal no Ringer resfriado, não se nota a princípio reação alguma. Em seguida, surgem pequenas contrações fibrilares, que se vão pouco a pouco intensificando e fundindo-se gradual- 
mente em uma fase tônica, durante a qual ficam contraídos em extensão os membros posteriores.

Depois da fase tônica, inicia-se a terceira fase do ataque: a fase clônica, em que teremos convulsões dêste tipo, cuja freqüência e fôrça vão progressivamente diminuindo, até a imobilidade total do trem posterior.

Após o ataque, desaparecem os reflexos. Podemos recuperá-los, imergindo a medula espinhal num banho de Ringer, durante alguns minutos $(3,4)$.

\section{Ação da mianesina sôbre o ataque}

Realizamos uma série de 59 experiências com a rã do Rio de Janeiro, o Leptodactylus ocellatus, cujo pêso achava-se compreendido entre 18 e 103 gramas.

A preparação medula espinhal isolada-trem posterior foi feita após um tempo oscilando entre 23 e 76 minutos depois da injeção de mianesina.

De um modo geral, na maior parte das experiências, o intervalo que decorreu entre a administração da substância e o início da preparação foi de 25 a 50 minutos.

Os reflexos mostravam-se em flexão, com vivacidade aproximadamente normal, enfraquecidos porém em alguns casos.

Os resultados gerais acham-se expostos nos quadros I e II.

Nestes quadros temos 2 colunas nas quais se acham representados respectivamente o pêso da coluna vertebral e o produto $\left(P_{1} \cdot P_{m}\right)^{-2 / 3}$, em que $P_{1}$ é o período latente do ataque em minutos, e $P_{m}$ é o peso da coluna vertebral em gramas, valor êste estabelecido por Miguel Ozorio DE ALMeida e seus colaboradores, como sendo aproximadamente uma constante para uma determinada temperatura (4) .

No quadro I acham-se expostos os resultados de 37 experiências, nas quais utilizamos como banho refrigerante uma solução de Ringer, de temperatura superior a $0^{\circ} \mathrm{C}$.

Pelo exame dêste, verifica-se que as doses abaixo de $40 \mathrm{mg} / \mathrm{Kg}$ enfraquecem freqüentemente as manifestaçõs convulsivas, reduzindo-as por vêzes a fracos tremores das pernas.

Em um caso de 13 experiências houve mesmo abolição completa das manifestações motoras.

Doses mais elevadas determinaram a abolição do ataque em quasi todos os casos. 
QUADRO I

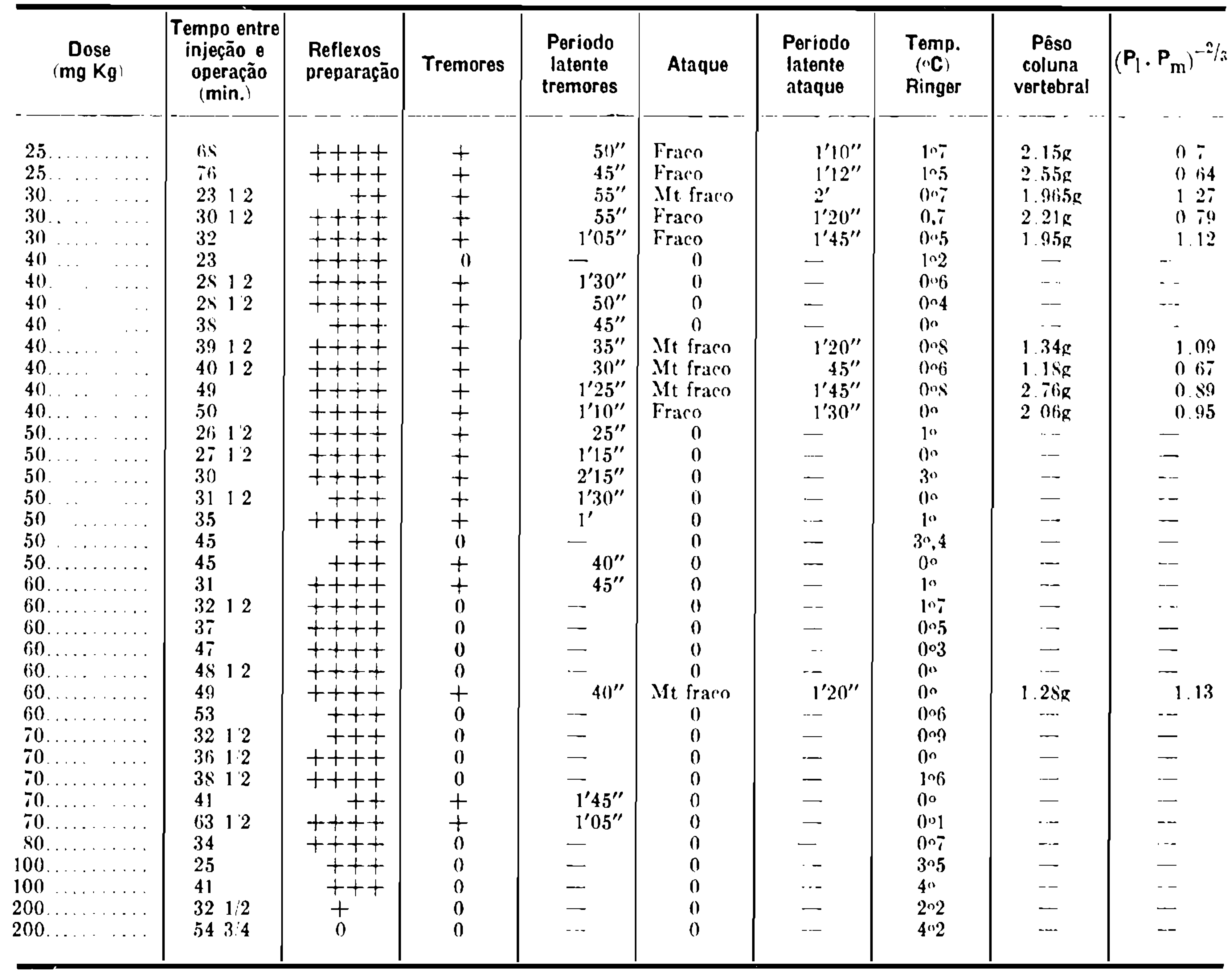

Reflexos da preparação --. 0 : ausentes; + : esbosados; ++ : fraros; +++ : medios; ++++ : vivos.

QUADRO II

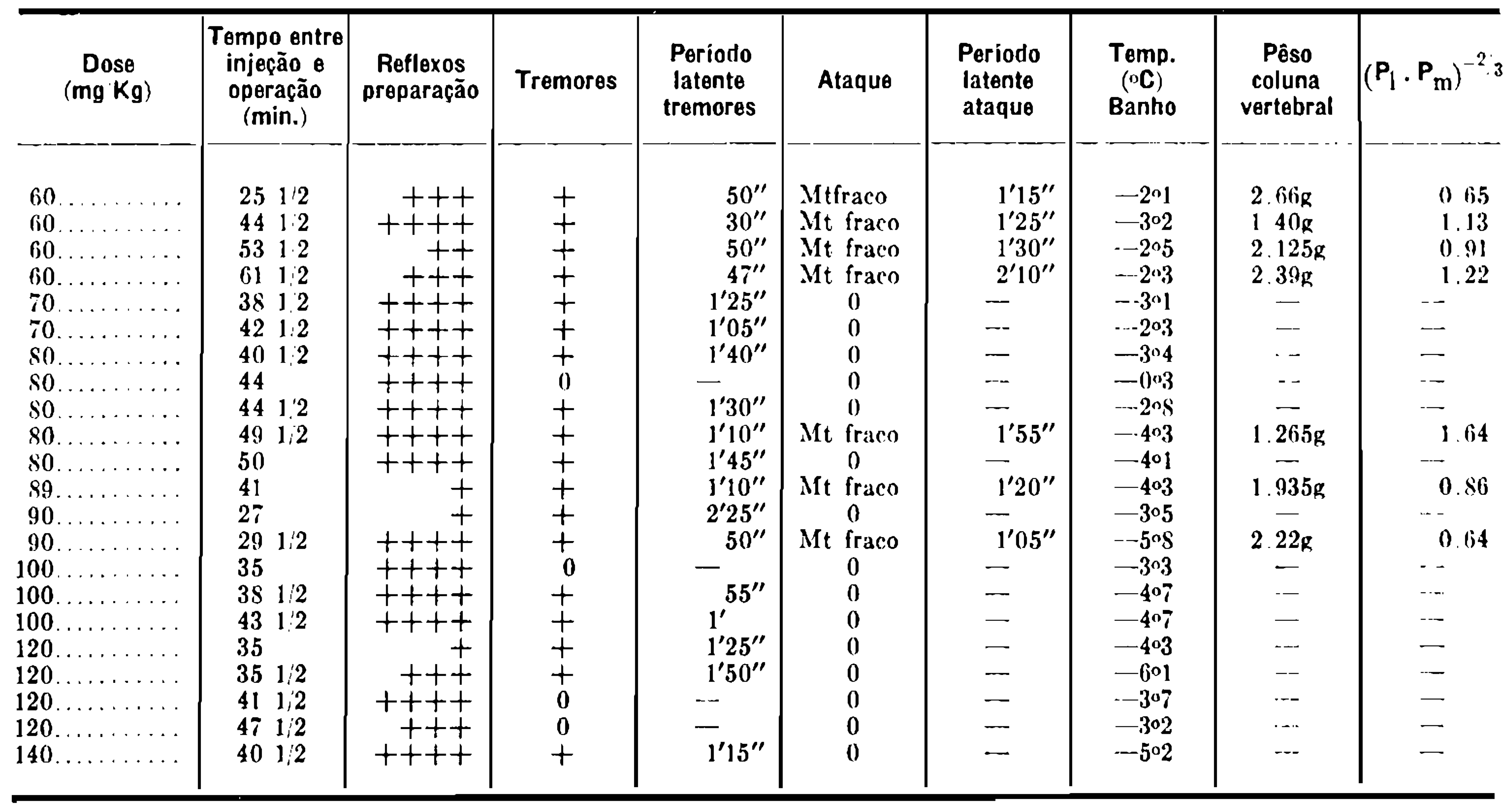


No quadro II, acham-se expostos os resultados de 22 experiências, nas quais utilizamos como banho refrigerante solução hipertônica de $\mathrm{NaCl}(10 \%)$, cuja temperatura inferior a $0^{\circ} \mathrm{C}$ achava-se situada entre $-0,3^{\circ}$ e $-6,1^{\circ} \mathrm{C}$.

Pelo exame dêste, verifica-se que as doses abaixo de $60 \mathrm{mg} / \mathrm{Kg}$ enfraquecem as manifestações convulsivas, permanecendo, não obstante, o ataque epileptiforme com suas caracteristicas próprias, muito embora diminuido na intensidade.

As doses mais elevadas, compreendidas entre 70 e $90 \mathrm{mg} / \mathrm{Kg}$ reduzem geralmente as manifestações convulsivas a tremores fracos das pernas.

Doses superiores a $100 \mathrm{mg} / \mathrm{Kg}$ determinaram a abolição do ataque em todos os casos.

\section{AÇÃO DA MIANESINA SÔBRE AS CONVULSÕES DA ESTRIQUININA}

Realizamos uma série de 37 experiências com o Leptodactylus ocellatus para verificar a ação da mianesina sôbre as convulsões estrícnicas.

Os resultados gerais acham-se expostos nos quadros III e IV.

No quadro III, acha-se representada uma série de 27 experiências nas quais injetamos mianesina, em doses diversas, e, após um intervalo de 11 a 39 minutos, em geral de 11 a 25 minutos, uma dose de $1 \mathrm{mg} / \mathrm{Kg}$ de estriquinina.

Convém ressaltar que esta dose já se acha estandardizada no Laboratório de Fisiologia do Instituto Oswaldo Cruz como a limiar convulsivante, produzindo, após um período latente de 20 a 30 minutos, o surto das convulsões típicas dêste alcalóide, que se conservam inalteradas por algumas horas.

Analizando-se o quadro III, observamos que a mianesina provocou um atrazo no surto das convulsões do alcalóide, sendo que, com doses compreendidas entre 200 e $250 \mathrm{mg} / \mathrm{Kg}$, manifestou-se apenas uma hiper-reflexia de tipo estrícnico.

Não notamos, porém, nas várias doses utilizadas a supressão completa dos efeitos da estriquinina, que, contudo, se manifestavam após uma latência maior.

No quadro IV, acham-se representadas 10 experiências, nas quais injetamos mianesina, em doses de 100 e $200 \mathrm{mg} / \mathrm{Kg}$, e, após um intervalo de 10 a 22 minutos, uma dose de $2 \mathrm{mg} / \mathrm{Kg}$ de estriquinina.

Pela análise do mesmo, observamos que, com uma dose de 200 $\mathrm{mg} / \mathrm{Kg}$, dose paralisante como já vimos, notou-se um ligeiro atrazo no surto das convulsões estrícnicas, que foram outrossim deprimidas em sua intensidade, denotando por conseguinte a existência de um antagonismo muito discreto, com tais quantidades. 
QUADRO III

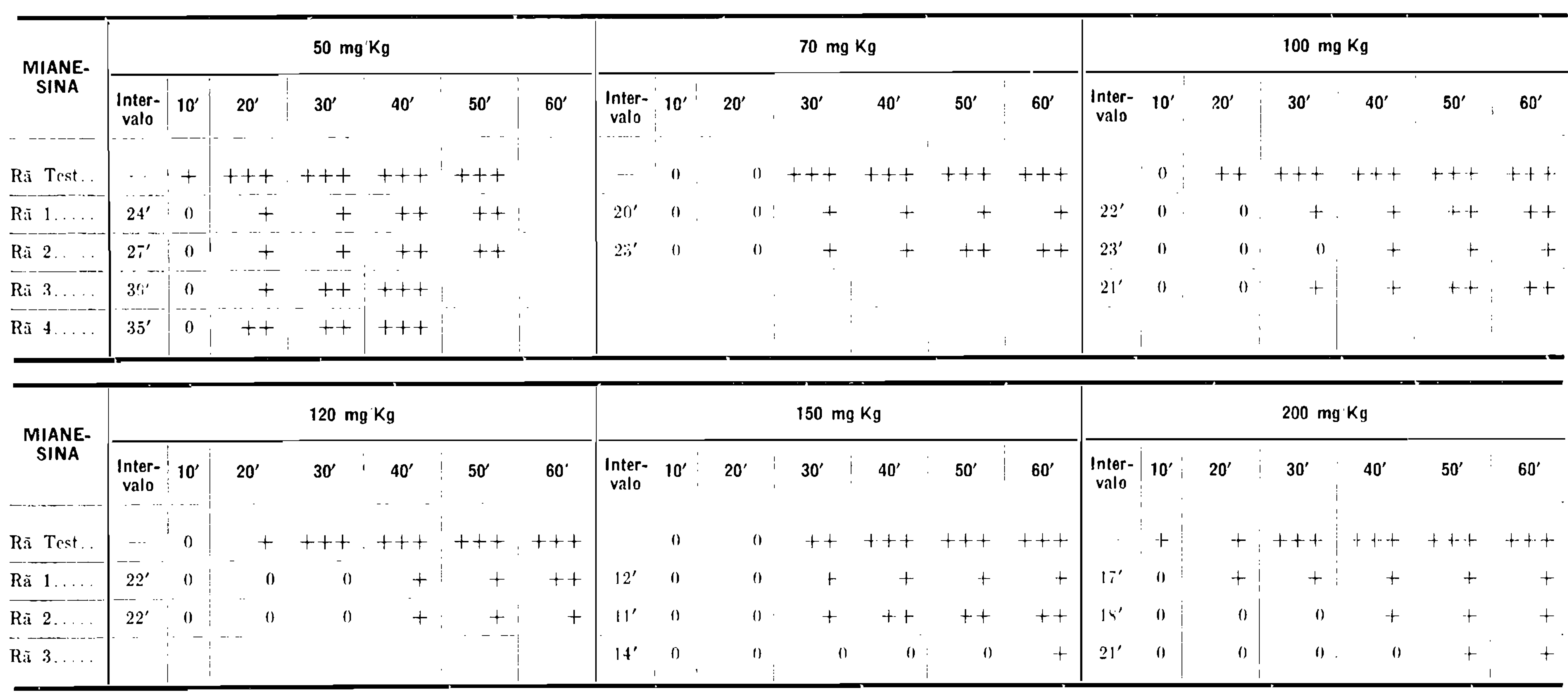

\begin{tabular}{|c|c|c|c|c|c|c|c|}
\hline \multirow{2}{*}{$\begin{array}{l}\text { MIANE- } \\
\text { SINA }\end{array}$} & \multicolumn{7}{|c|}{$250 \mathrm{mg} / \mathrm{Kg}$} \\
\hline & $\begin{array}{c}\text { Inter- } \\
\text { valo }\end{array}$ & $10^{\prime}$ & $20^{\prime}$ & $30^{\prime}$ & $40^{\prime}$ & $50^{\prime}$ & $60^{\prime}$ \\
\hline R̃̃ Test & $\cdots$ & + & + & $++t$ & +++ & $+t+$ & +++ \\
\hline Rã 1. & $19^{\prime}$ & 1) & 0) & 0 & 0 & + & + \\
\hline $\mathrm{Rã} 2$. & $1 i^{\prime}$ & 0 & n) & 0 & 0 & + & + \\
\hline Rã 3. & $2 I^{\prime}$ & 0) & 0 & 0 & 0 & + & + \\
\hline
\end{tabular}

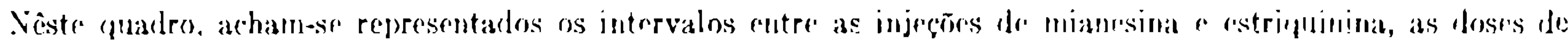
mianesila o o estado geral posterior do animal, assim escruernatizado:

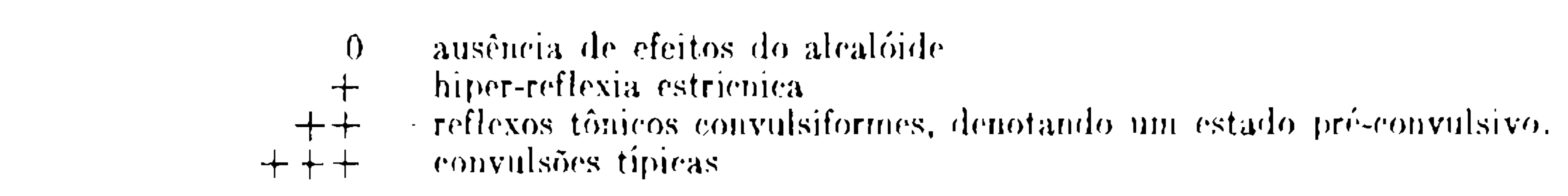


QUADRO IV

\begin{tabular}{|c|c|c|c|c|c|c|c|c|c|c|c|c|c|c|}
\hline \multirow{2}{*}{$\begin{array}{l}\text { MIANE. } \\
\text { SINA }\end{array}$} & \multicolumn{7}{|c|}{$100 \mathrm{mg} / \mathrm{Kg}$} & \multicolumn{7}{|c|}{$200 \mathrm{mg} / \mathrm{Kg}$} \\
\hline & Intervalo & 10 & $20^{\prime}$ & $30^{\prime}$ & $40^{\prime}$ & $50^{\prime}$ & $60^{\prime}$ & Intervalo: & $10^{\prime}$ & $20^{\prime}$ & $30^{\prime}$ & $40^{\prime}$ & $50^{\prime}$ & $60^{\prime}$ \\
\hline Rã T'est. & - & + & $+t+$ & +++ & $++t$ & +++ & $+t+$ & - & + & +++ & $+1+$ & $+t+$ & +++ & +++ \\
\hline Râa 1. & $19^{\prime}$ & ++ & $+t+$ & $++t$ & $+t+$ & +++ & $+t+$ & $2 \cdot 2^{\prime}$ & + & $+t$ & ++ & $+t$ & +++ & $+t+$ \\
\hline Rã 2. & $21^{\prime}$ & ++ & ++ & +++ & +++ & +++ & +++ & $22^{\prime}$ & + & ++ & ++ & ++ & ++ & +++ \\
\hline Rã $3 \ldots$. & $10^{\prime}$ & ++ & ++ & ++ & +++ & +++ & $+t+$ & $10^{\prime}$ & + & ++ & ++ & ++ & ++ & ++ \\
\hline Rã 4. & $11^{\prime}$ & ++ & ++ & ++ & +++ & +++ & +++ & $12^{\prime}$ & + & ++ & ++ & ++ & ++ & +++ \\
\hline
\end{tabular}




\section{AÇÃO DA MIANESINA SÔBRE A CONTRATURA DA PATA DO COELHO ESPINHAL PRODUZIDA PELO ARRANCAMENTO DA PELE DO MESMO}

Esta contratura foi obtida pela primeira vez por Miguel Ozorio de Almeida e Henri Piéron $(17,18)$, tendo conseguido uma hipertonia da perna do coelho espinhal quando se arrancava a pele da mesma.

Realizamos uma série de 5 experiências no coelho espinhal, tendo sido prèviamente arrancada a pele de uma das pernas .

Seccionamos em primeiro lugar a medula espinhal ao nivel das últimas dorsais, com o fito não só de impedir a dôr como também eliminar os movimeritos voluntários do animal.

Desenvolve-se a contratura $\epsilon \mathrm{m}$ flexão 2 a 3 hoias apj́s o arrancamento da pele, servindo assim o animal para o estudo não só da ac̣ão de uma substância sôbre a contratura, como também sôbre o estado geral, que se revela pela vivacidade do coelho, atitude da cabeça, correção quando colocado de costas, etc... que se tornam normais pouco após a operação.

Nas doses utilizadas (25 a $30 \mathrm{mg} / \mathrm{Kg}$ ), a mianesina, injetada lentamente na veia da orelha (cêrca de $1 \frac{1 / 2}{2}$ a 2 minutos), provocou diminuição ou mesmo abolição da contratura cêrca de $3 \frac{11}{2}$ a 4 minutos após a injeção.

Os reflexos patelares sofreram pouca alteração, tornando-se enfraquecidos em um caso apenas. O estado geral apresentou ligeira depressão, manifestando-se o tônus da cabeça diminuido em grau moderado e a correção se fazendo com alguma dificuldade.

Os efeitos da mianesina revelaram-se bastante fugazes, notando-se ao fim de poucos minutos (13 a 19) desaparecimento dos sinais descritos e retôrno da contratura.

Em um caso, observamos, durante minutos, logo após a injeção, acentuada rigidês dos membros anteriores, lembrando a rigidês de descerebração.

\section{DISCUSSÃO}

Berger e Bradley obtiveram, na rã européia (Rana temporaria), paralisia flácida e cessação dos movimentos respiratórios por injeção de mianesina no saco linfático ventral, chegando até a perda da excitabilidade indireta dos músculos em doses que causavam paralisia reversível (7) .

Contudo Finkelman e Arieff negam a ação curarizante da mianesina, por experiências realizadas em gatos e rãs européias (9) .

Em nossas experiências com o Leptodactylus ocellatus, obtivemos, utilizando doses de 150 a $250 \mathrm{mg} / \mathrm{Kg}$ paralisia flácida, conservando-se contudo os movimentos respiratórios. 
Também foi estudada a ação da mianesina sôbre a crioepilepsia, tendo sido abolidos os movimentos convulsivos com doses de $50 \mathrm{mg} / \mathrm{Kg}$, a temperatura superior a $0^{\circ} \mathrm{C}$, e até $100 \mathrm{mg} / \mathrm{Kg}$, a temperatura inferior a $0^{\circ} \mathrm{C}$, conforme expusemos nos quadros I e II.

A ação da mianesina sôbre as convulsões da estriquinina tem sido bastante estudada por vários autores.

Trabalhos de BERGER e BRAdLey $(5,7)$ revelam ação antagônica, em ratos, destas 2 substâncias, ação esta diferente da produzida pelos barbitúricos, uma vez que em doses insuficientes para causar paralisia, seria capaz a mianesina de suprimir os efeitos estrícnicos (6).

Com êste resultado, sugere BERGER a hipótese de que a mianesina e a estriquinina agiriam no mesmo neurônio da medula espinhal, ou seja, o neurônio internuncial, que após tratado pela mianesina se tornaria insensível aos efeitos do alcalóide.

Nossos resultados com o Leptodactylus ocellatus diferem um pouco dos de BERGER, uma vez que realmente observamos antagonismo de efeitos entre estas 2 substâncias, contudo não tão absoluto, como o afirma êste autor.

Uma dose paralisante de mianesina, qual seja a de $200 \mathrm{mg} / \mathrm{Kg}$, impede o surto das convulsões pela estriquinina, após a injeção de uma dose limiar convulsivante do alcalóide. Não obstante, surgem sinais de intoxicação estrícnica, tais como hiperreflexia generalizada e, por vêzes, reações denotando certa tonicidade.

Esta mesma dose é ineficaz para se opor aos efeitos da estriquinina, injetada em dose de $2 \mathrm{mg} / \mathrm{Kg}$, surgindo as convulsões típicas com algum atrazo e um tanto deprimidas na sua intensidade.

Finalmente, realizamos uma série de experiências estudando a ação da mianesina sôbre a contratura em flexão da perna do coelho espinhal, produzida experimentalmente pelo arrancamento da pele da mesma.

Esta contratura é de origem reflexa e motivada pelos estímulos nervosos aferentes que se intensificam com o arrancamento da pele, pois que ficam dilacerados vários filetes nervosos expostos ao ar, que originarão excitações responsáveis pela hipertonia verificada.

Também a perna contralateral apresenta um aumento do tônus embora em grau menor $(17,18)$.

A mianesina, em doses de 25 a $30 \mathrm{mg} / \mathrm{Kg}$, diminuiu ou mesmo aboliu a contratura, exercendo certo grau de depressão no estado geral do coelho. Estes efeitos são fugazes, uma vez que de acôrdo com as experiências de TITUS, ULICK e RICHARDSon, a mianesina desaparece ràpidamente da corrente sanguínea, assim se explicando sua ação efêmera, quando injetada por via intravenosa (10) .

Em um caso, notamos certa rigidês dos membros anteriores, pouco após injetada a mianesina, rigidês esta que lembrava a de descerebração e já tendo sido descrita por outros autores $(8,11)$. 
Podemos explicá-la, como se processando uma secção farmacológica, motivada pela ação deprimente da droga em certas estruturas do mesencéfalo, e não a uma ação direta sôbre o músculo (8).

Êstes resultados vêm indicar, assim como todos os anteriores, que a mianesina exerce nítida ação deprimente sôbre o sistema nervoso central, especialmente sôbre a medula espinhal.

À luz desta interpretação, poderemos explicar todos os nossos resultados obtidos, a saber: tral.

a) A ação sôbre o organismo intacto revela ação deprimente cen-

b) A ação anticonvulsivante em relação à crioepilepsia só pode ser interpretada, admitindo-se uma depressão na medula espinhal.

c) Da mesma maneira, pode ser explicada a ação anticonvulsivante desta substância em relação à estriquinina, ação esta que não seria contudo suficiente para impedir o surto dos efeitos típicos do alcalóide, vindo a lançar dúvidas sôbre se, realmente, como o afirma BERGER, a ação da mianesina e estriquinina se faz sôbre o neurônio internuncial e que, êste, tratado prèviamente por uma dose abaixo da paralisante de mianesina, se torna insensível aos efeitos da estriquinina.

d) Finalmente, inclinamo-nos a admitir ação central, ou melhor, na medula espinhal, no caso da abolição da contratura de origem reflexa no coelho espinhal, uma vez que tanto a conservação do reflexo patelar, quanto a do tônus da cabeça parecem afastar a possibilidade de intervenção periférica da mianesina.

\section{RESUMO E CONCLUSÕES}

1) Neste trabalho, expusemos a ação da mianesina sôbre o organismo do Leptodactylus ocellatus, sôbre as convulsões da crioepilepsia e estriquinina produzidas experimentalmente no mesmo e também a ação desta substância sôbre a contratura em flexão da perna do coelho espinhal produzida pelo arrancamento da pele da mesma.

2) A mianesina provocou em doses de 150 a $200 \mathrm{mg} / \mathrm{Kg}$ paralisia flácida no Leptodactylus ocellatus.

3) A mianesina revelou-se capaz de suprimir os movimentos convulsivos de tipo epileptiforme, obtidos pelo resfriamento brusco da medula espinhal.

4) No Leptodactalus ocellatus o antagonismo da mianesina e estriquinina não é muito acentuado e doses paralisantes da primeira são ineficazes para impedir o surto dos efeitos do alcalóide.

5) A mianesina provocou uma abolição na contratura em flexão da perna do coelho espinhal motivada pelo arrancamento da pele da mesma. 


\section{BIBLIOGRAFIA}

1. Berger, F.M. and Bradley, W.,

The Lancet, 18, 1947, 97.

2. RILEY, R.F. and BERgER, F.M.,

Archives of Biochemistry, vol. 20, 1949, N.० 1.

3. Ozorio de Almeida, M., Moussatché, H. e Vianna Dias, M., Rev. Brasil. Biol., 1(2) : 179-194, 1941.

4. Ozorio de Almeida, M., Moussatché, H. e Vianna Dias, M., Rev. Brasil. Biol., 2(4) : 455-471, 1942.

5. BERGER, F.M.,

The Journal of Pharmacology and Exptl Therapeutics 1949, vol. 96. n. 4, 249 .

6. BERGER, F.M.,

Quarterly Journal of Pharmacy and Pharmacol. vol. 20, n. ${ }^{\circ}$ 2, 1947, 94.

7. Berger, F.M. and BRAdLEy, W., Brit. Journal Pharmacol. 1946, 1, 265.

8. BERGER, F.M., Brit. Jour. Pharm. 1947, 2, 241.

9. Isidoro Finkelman, M.D. and ARIEFF, A.J., M.D., The Journal of Nervous and Mental Diasease, vol. 109, n. ${ }^{\circ} 4,1949,326$.

10. Titus, E., Ulick, S. and RICharson, A.P. The Journal of Pharmac. and Exptl. Therapeutics, 1948, vol. 93, n. ${ }^{\circ} 2$,
129 .

11. BURKE, J.C. and LINEGAR, C.R., Federation Proc. $7: 208,1948$.

12. NicolaU, J.C., Revista Clínica Española - t. 33, 1949, n. ${ }^{\circ} 1$.

13. Mallinson, F.B., M.R.C.S., D.A., The Lancet - n. ${ }^{\circ} 6438-1947,252$.

14. Henneman, E. and Scherrer, J., The Journal of Pharmacology and Exptl Therapeutics, Vol. 97, 1949, n. 3.

15. Finkelman, I., M.D., and Dobin, M.B., M.D., The Journal of Nervous and Mental Disease - vol. 109, n. $.^{4}, 1949$.

16. BERGER, F.M., Jour. Pharmacol. 93, 470-81, 1948.

17. Ozorio de Almeida, M. et PiÉRon, H., Comptes rendus de la Soc. de Biol. - 1924 - t. 90, 1402.

18. Ozorio DE Almeida, M.

Comptes rendues de la Soc. de Biol., 1933, t. 14, 834. 